\title{
New generation of super duplex steels for equipment gas and oil production
}

\author{
Leonid Levkov, Dmitry Shurygin*, Vladimir Dub, Konstantin Kosyrev, and Alan Balikoev, \\ CNIITMASH JSC, 115088, Sharikopodshipnikovskaya str. 4, Moscow, Russia
}

\begin{abstract}
Oil\&gas producing industry today is increased production volumes from old deposits on land, offshore and deep-water. The materials used to create modern equipment that meets these trends should be distinguished by increased productivity in conditions of corrosion and high pressure, to ensure trouble-free operation. In such conditions, taking into account the necessary provision of acceptable cost indicators, there is no alternative to duplex steels. Their crystal structure simultaneously allows using the advantages of ferritic and austenitic phases. The report presents the results of using a compositional and technological methods for structure management, the rationale alloying with copper (3.0-3.3\%). Application of ESR in the manufacture of steel billets of super duplex steel has demonstrated the ability to simultaneously achieve physical, chemical and structural homogeneity, ensuring high corrosion\&mechanical characteristics. The thermodynamic and kinetic conditions for the formation of optimal phase steel composition are determined. Grounded heat treatment regimes, prevent the formation of sigma and psi-phase and contribute to the formation of stable intermetallides $(30-300 \mathrm{~nm})$. Based on the test results of "Gazprom-VNIIGAZ" LLC the new steel is recommended for the manufacture of valve bodies and in-vessel internals used in the fields, that containing $\mathrm{H}_{2} \mathrm{~S}$ and $\mathrm{CO}_{2}$ up to $25 \%$ in the fluid.
\end{abstract}

\section{Introduction}

Recently, oil and gas production industry increases the extraction volumes of hydrocarbons from offshore and deep-water wells, boosts production from old fields [1]. The materials used to create modern equipment that meets these trends should be distinguished by increased productivity in conditions of corrosion and high pressure, to ensure trouble-free operation. Austeniteferritic super duplex stainless steels (SDSS) are practically have no alternative for such operating conditions with taking into account the provision of acceptable cost indicators. They possess a unique combination of mechanical and corrosion properties among stainless steels, satisfactory weldability without heating, and good machinability. The cost of products made from that steels is small compared to the cost of products made of nickel alloys and titanium $[2,3]$ and can compete with the cost of products made of structural steels with corrosion-resistant overlaying.

Modernization of the SDSS to solve various objectives is ensured by improving the metallurgical quality of the billets. Today, Russian companies are faced with the urgent need to organize their own production of high-tech equipment.

Engineering solutions for such equipment should be based on the use of perspective materials of domestic production, capable of withstanding high corrosion and mechanical load without the danger of brittle fracture.

\section{New generation of duplex steels}

Duplex steels owe their name to a two-phase austeniticferritic structure with a phase ratio of approximately $1: 1$ (Fig. 1). Soft ferrite gives steel good plastic properties and prevents chloride-induced corrosion cracking, to which austenite is so sensitive. Austenite provides high corrosion resistance [4,5]. This combination of properties is the main advantage of duplex steels. Ferrite and austenite interfere with the growth of grains which provides high tensile strength and yield strength.

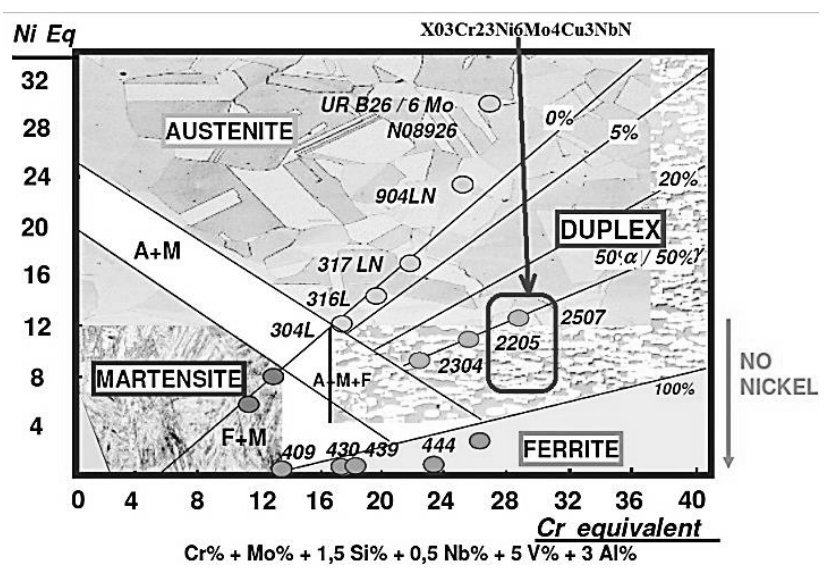

Fig. 1. Position of steels of various classes on the Scheffler phase diagram [6] 
Despite the above advantages of SDSS, there are reasons that slow down their spread:

- Increased strength is considered one of the drawbacks when it comes to the manufacturability of deformation processing, which is somewhat lower than that of austenitic steels. Consequently, the developed SDSS compositions and technologies for their production should provide high plasticity characteristics of the material in the hot and cold state.

- Another problem is related to the fact that even with small deviations from the technology, undesirable secondary phases may generate during the cooling of the billet. The formation of a sigma phase, significantly reducing the properties of SDSS, is noted when there is a shortage of the cooling rate after heating with a solid solution or welding with forced modes.

- Typically, the $475{ }^{\circ} \mathrm{C}$ embrittlement observed during the formation of the phase, which is called $\alpha^{\prime}$ (alpha prime). It should be noted that the embrittlement can occur and at a temperature of $300{ }^{\circ} \mathrm{C}$, which causes a corresponding limitation of the maximum temperature of use of the products from SDSS.

- The transition temperature of fragility of most SDSS exceeds $-60{ }^{\circ} \mathrm{C}$. Although it is known that methods based on technologies of sequential melting have additional opportunities to reduce this threshold.

One of the known technological methods that allow to improve plastic characteristics of metal without decreasing of tensile strength and improve its chemical, physical and structural isotropy is electroslag remelting (ESR) $[7,8]$. During this process, as well as other sequential melting processes, at any given moment in time there is a relatively small mass of metal $(3-10 \%$ of the total mass of the ingot) in the liquid state. This allows to influence with most effectively on dynamics of solidification not only by thermal and compositional, but also by special methods. This constitutes an important reserve for expanding the scope of use of SDSS for products that require high technological plasticity.

The modernization of SDSS compositions is aimed at eliminating the effect of weakening of grain boundaries from large chromium carbides, replacing them with small niobium nitrides and carbonitrides which that are not capable to coagulation at dispersion-strengthening ferritic grains. At the stage of crystallization, a dense uniform distribution of ferritic and austenitic grains in the primary structure of the ingot is provided. This helps to increase the efficiency of thermal deformation redistribution (Fig. 2).

Specialists of «CNIITMASH» JSC have developed a corrosion-resistant rationally alloyed steel grade $\mathrm{X} 03 \mathrm{Cr} 23 \mathrm{Ni} 6 \mathrm{Mo} 4 \mathrm{Cu} 3 \mathrm{NbN}$ (after ESR) and end-to-end technology production therefrom forgings. From the known SDSS (Table 1), the new developed composition is distinguished by reduced contents of expensive alloying elements (Ni, Mo, Cr). However, it is characterized by a high value of the indicator $\mathrm{PRE}_{\mathrm{N}}>45$ and mechanical properties.

The results of thermodynamic and mathematical modeling used in the development of the chemical composition of the new SDSS confirmed the reasonability of alloying the SDSS with copper, niobium, nitrogen, and also modifying REM and calcium [9] instead of the traditional increase in chromium content to $26-29 \%$ (S2707HD) or $29-33 \%$ (S3207HD) and molybdenum (up to $5 \%$ ), which increases the likelihood of separation of secondary phases. This is confirmed by the authors [17] when comparing duplex steels $1.4162([\mathrm{Cr}]=21.57 \%$, and $1.4662([\mathrm{Cr}]=24.41 \%)$. After heat treatment, only chromium nitrides were found in the intercritical temperature range in 1.4162 steel, while in steel 1.4662 a significant $\sigma$-phase release was observed if the duration of exposure was more than an hour.

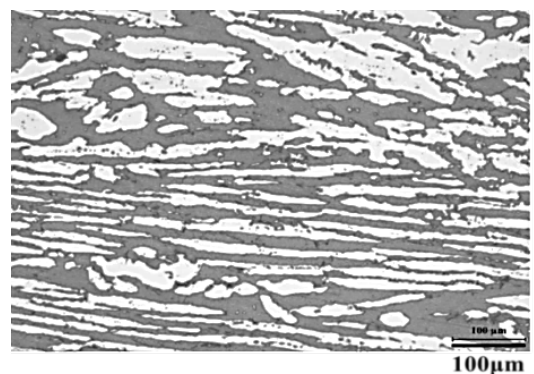

a)

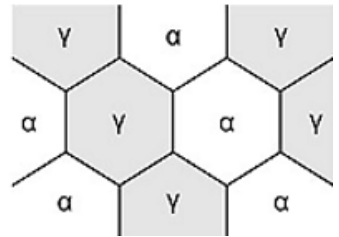

b)

Fig. 2. Microstructure of SDSS:

a) steel $\mathrm{X} 03 \mathrm{Cr} 23 \mathrm{Ni} 6 \mathrm{Mo} 4 \mathrm{Cu} 3 \mathrm{NbN}$ (after ESR) after thermodeformation redistribution; b) schematic representation of phase distribution in duplex steel.

In the structure of the developed steel, copper is concentrated on the surfaces of the grains, the inner surface of micropores and microcracks, exerting an inhibitory effect on the reaction rate of hydrogen sulfide with carbon steel in the presence of moisture.

Due to the formation of copper sulfide and its eutectic (the solid solution strengthening copper-containing phase) was an increase in strength and plastic characteristics, positive change the macro- and microstructure at room temperature and after aging. The observed positive effect of alloying copper SDSS and confirm the results of [18], where the steel Duplok 27, contained $25.45 \%$ [Cr], $6.32 \%$ [Ni], 2.76\% [Mo], $1.61 \%$ $[\mathrm{Cu}]$ and $0.26 \%[\mathrm{~N}]$, which was an increase in the mechanical properties and decrease precipitates of secondary phases.

The alloying of steel with nitrogen in combination with a nitride-forming element - niobium allows to formate of fine nitrides and carbonitrides which are uniformly distributed in the matrix. These particles, unlike carbides, are not prone to coagulation, inhibit 
grain growth and implement the dispersion hardening mechanism.

Table 1. Mechanical properties of metal forgings of reference duplex steels at $+20{ }^{\circ} \mathrm{C}$

\begin{tabular}{|l|c|c|c|c|c|}
\hline \multicolumn{1}{|c|}{ Duplex steel } & $\begin{array}{c}\text { Tensile } \\
\text { strength } \\
\sigma_{\mathrm{B}} \\
\mathrm{MPa}\end{array}$ & $\begin{array}{c}\text { Yield } \\
\text { strength } \\
\sigma_{0,2} \\
\mathrm{MPa}\end{array}$ & $\begin{array}{c}\text { Elongation } \\
\delta, \% \\
\text { not less }\end{array}$ & $\begin{array}{c}\text { Contraction } \\
\text { ratio } \\
\psi, \% \\
\text { not less }\end{array}$ & $\begin{array}{c}\text { Impact } \\
\text { strength } \\
\mathrm{KCV}, \mathrm{J} / \mathrm{cm}^{2} \\
\text { not less }\end{array}$ \\
\hline SAF 2507[10] & $730-900$ & $530-650$ & 20 & 40 & 100 \\
\hline SAF 2707HD [11] & $920-1100$ & $\geq 700$ & 25 & - & $230^{1)}$ \\
\hline SAF 3207 [12] & $\geq 770$ & $\geq 950$ & 25 & - & $110^{1)}$ \\
\hline$[13]$ & $\geq 840$ & $620-680$ & 17 & 27 & no data \\
\hline Duplok 27 [14] & $\geq 850$ & $\geq 550$ & 23 & - & - \\
\hline ZI 130 (03Cr24Ni6Mo3N) [15] & $\geq 690$ & $\geq 390$ & 25 & 40 & 60 \\
\hline X03Cr23Ni6Mo4Cu3NbN (after ESR) [16] & $\geq 830$ & $\geq 660$ & 25 & 54 & 120 \\
\hline
\end{tabular}

Note: ${ }^{1)}$ cold-drawn pipes with a wall thickness of less than $4 \mathrm{~mm}$.

\section{Result and discussion}

A special feature of the technology of production of the new SDSS steel is the use of electro-slag remelting in the processing chain. Smelting of ingots was carried out on a unique scientific furnace ESR-0.5U in «CNIITMASH» JSC [16]. Developed technology of ESR with using lowfrequency AC. To eliminate the loss of alloying elements during remelting and maintaining a stable low oxidation level of slag the oxidation process [19] was applied. Ingots weighing up to $50 \mathrm{~kg}$ were subjected to forging on a hydraulic hammer with forging grade 4 , the forgings were subjected to heat treatment according to the mode: 1050-1070 ${ }^{\circ} \mathrm{C}$, holding in an furnace, rapid cooling.

The positive effect of managing the depth of the metal bath and the depth of the two-phase zone (mushy zone) ensured macro- and microstructure uniformity, favorable morphology and topology of non-metallic inclusions.

The microstructure of the new SDSS (Fig. 3a) is represented by $\delta$-ferrite $(\approx 57 \%)$ and austenite. The size of ferritic grain is estimated by number G8-11, and the average value of the gap between austenite grains is 20 $\mu \mathrm{m}$. The intermetallic phase having the largest (about $0.5 \%$ ) volume fraction is $\mathrm{NbCr}_{2}$ (Fig. $3 \mathrm{~b}$ ).

Calculated, taking into account the optimized composition of the steel, the heat treatment mode allows to prevent the formation of $\sigma$ - and $\chi$-phases during the quenching of the solid solution and ensured the formation of stable niobium nitrides and carbonitrides with effective diameters of 30-300 nm which are reinforcing the ferritic matrix.

The advantages of steel $\mathrm{X} 03 \mathrm{Cr} 23 \mathrm{Ni} 6 \mathrm{Mo} 4 \mathrm{Cu} 3 \mathrm{NbN}$ (after ESR) over most of the currently used SDSS are determine the prospect of its use for the production of equipment operating under high corrosion-mechanical loads, without the risk of brittle fracture.

Tests carried out in accordance with standard NACE TM0177-2005 (Method A) by "Gazprom-VNIIGAZ" LLC [20] confirmed high resistance of steel $\mathrm{X} 03 \mathrm{Cr} 23 \mathrm{Ni6Mo} 4 \mathrm{Cu} 3 \mathrm{NbN}$ (after ESR) against hydrogen sulfide stress cracking (SCC). During the $720 \mathrm{~h}$ test cycle at an applied strain of $0.8 \sigma_{\mathrm{T}}$, the fracture of the specimens, as well as cracks, was not recorded. The rate of general corrosion in environments containing $\mathrm{H}_{2} \mathrm{~S}$ and $\mathrm{CO}_{2}$ up to $25 \%$ is no more than $0.0013 \mathrm{~mm} /$ year. In the investigation of samples with up to 50 fold increase in pitting are not detected. Test samples drum with a sharp notch $\langle\mathrm{V} »$ showed an average value of fracture energy $27.3 \mathrm{~J}$ at a temperature of $-46^{\circ} \mathrm{C}$. This result satisfies the requirements of GOST R 51365-2009 for equipment intended for operation in climatic version «U» $\left(\mathrm{KV}^{-46}\right.$ > $20 \mathrm{~J}$ ), at the same time there is a significant reserve for lowering the transition temperature of fragility (FATT).

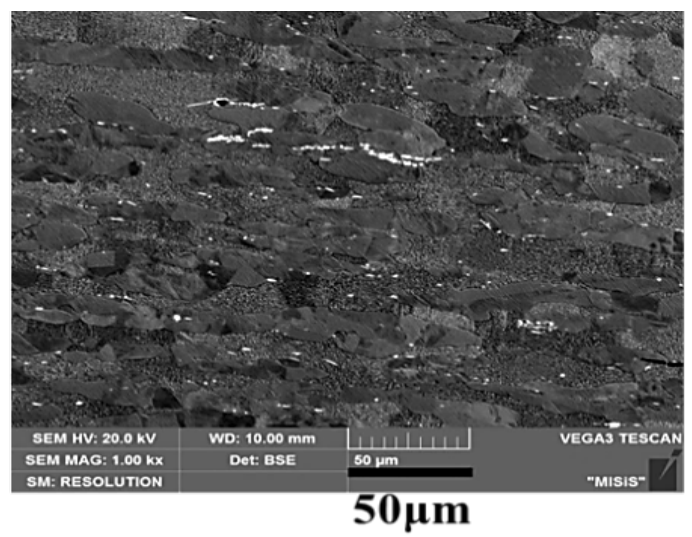

a)

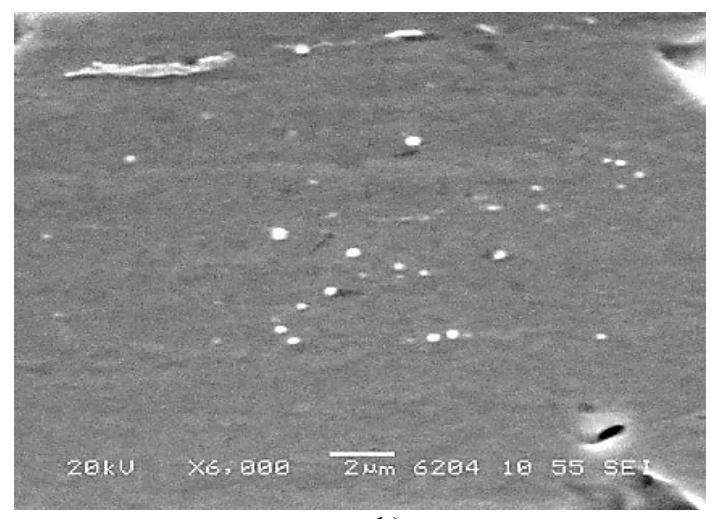

b)

Fig. 3. Photographs of the microstructure of $\mathrm{X} 03 \mathrm{Cr} 23 \mathrm{Ni6Mo4Cu3NbN}$ (after ESR) steel samples obtained 
using scanning electron microscopes: a) austenitic and ferritic phases; b) nano-sized carbonitrides and niobium nitrides (light globules), large light particles in the upper part of the frame a), which located on the grain boundaries - $\mathrm{NbCr}_{2}$ intermetallic compounds.

Thus, as a result of modernization of the chemical composition, the formation of a homogeneous fine crystalline structure, exceptions localization of large chromium carbides at the intergrain boundaries, dispersion strengthening ferrite fine (nanosized) nitrides and carbonitrides of niobium a steel $\mathrm{X} 03 \mathrm{Cr} 23 \mathrm{Ni6Mo4Cu} 3 \mathrm{NbN}$ (after ESR) has corrosion and mechanical properties, improved by compared with known SDSS. This determines the prospect of using new steel for the manufacture of not only mining equipment, but also desalination plants, carbamide recycling, sulphate pulping, metal structures of offshore platforms which are operating at high specific loads and pressures.

Production of equipment from the patented nanostructured SDSS will not only reduce the import dependence of oil and gas and chemical engineering, but also can significantly increase their export potential.

\section{Conclusion}

A composition of new nanostructured corrosion-resistant super duplex steel and the technology for the production of forgings from it were developed.

The test results allows to consider a new steel as a promising structural material with high mechanical properties, not prone to brittle fracture, stable in aggressive environments, including those with a high content of hydrogen sulfide and carbon dioxide, to recommend this steel for the manufacture of surface and offshore hydrocarbon production equipment.

The scope of application of new steel includes, but is not limited to, valve bodies and in-vessel internals of shut-off and control valves for critical equipment for gas and oil production equipment, wellhead equipment and related devices, as well as pumping equipment.

\section{References}

1. International Energy Agency, World Energy Outlook, (2012).

2. https://www.schmolz-bickenbach.ru (date of the application 11.01.2019).
3. J.-C. Gagnepain, J. Stainless Steel World, December (2008), P. 31-36.

4. A.S. Zubchenko, A.V. Fedorov, J. Welding and Diagnostics, 2 (2010), P.15-21.

5. I. Calliari, M. Pellizzari, M. Zanellato, E. Ramous, J. Materials Science, 46 (2011), P.6916-6924.

6. J. Charles, Proc. of Int. Conf. Duplex'07, Grado, Italy, (2007), 10p.

7. L.Ya. Levkov, D.A. Shurygin, V.S. Dub, V.V. Klochai, J. Chernye metally, 11 (2018), P.75-80.

8. V.S. Dub, L.Ya. Levkov, D.A. Shurygin, D.S. Tolstykh, V.V. Klochai, E.L. Korzun, A.A. Garchenko, J. Metallurgist, 62, 5-6 (2018), pp. 511520.

9. L.Ya. Levkov, Proc. of Conf. "Fittings for the oil and gas complex' 2019: Production and operation of the pipeline fittings and wellhead equipment. Problems and development prospects», April (2019), Tyumen.

10. https://www.materials.sandvik/en/materialscenter/material-datasheets/ (date of the application 30.11.2018).

11. Sandvik Materials Technology, Sandviken (2006)8p.

12. https://www.materials.sandvik (date of the application 01.04.2019)

13. A. Sundstrom, P. Kangas, Eurasian patent №009108, Publ. 2007.10.26.

14. O. Smuk, H. Hanninen and J. Liimatainen, J. Materials Science and Technology, 20 (2004), P.641644.

15. A.S. Zubchenko, M.M. Koloskov, Yu.V., Kashirsky and others. Marker steel and alloys. 2nd ed. (M.: Mashinostroenie), (2003), 784 p.

16. K.N. Utkina, A.G. Balikoev, L.Ya. Levkov et al., Proc of the 19th Conf. Young specialists in nuclear power, Podolsk, (2017), P. 351-359.

17. I. Calliari, M. Breda, M. Frigo, M. Pellizzari, E. Ramous, J. Vestnik MGTU im. G.I. Nosov, 4 (2014), P. 44-53.

18. O. Smyk. Doctoral Thesis. Royal Institute of Technology, Sweden. (2004), 42p.

19. L.Ya. Levkov, D.A. Shurygin, V.S. Dub, S.V. Orlov, K.N. Utkina, P.A. Gamov, Patent № 2630100 (RU), Publ. 09.05.2017.

20. L.Ya. Levkov, Proc. of the 2nd Int. Conf. "Corrosion in the oil and gas industry", section 3 (2017), P.8697. 